INNOVATIONS IN PRIMARY CARE

\title{
Increasing Naloxone Availability in Rural Communities
}

Nicholas B. West $t^{1}$

Will Hockett ${ }^{1}$

Nicolas Powers ${ }^{2}$

Rebecca E. Cantone, MD'

${ }^{1}$ Oregon Health \& Science University, Portland, Oregon

${ }^{2}$ Winding Waters Clinic, Enterprise, Oregon

Ann Fam Med 2019;17:178. https://doi.org/10.1370/afm.2374.

\section{THE INNOVATION}

The Centers for Disease Control and Prevention (CDC) Guideline for Prescribing Opioids for Chronic Pain states that there is a significant increase in morbidity and mortality for patients prescribed over 50 morphine equivalent doses (MEDs) and recommends co-prescribing naloxone to these patients. ${ }^{1}$ Furthermore, expanded availability to naloxone administration for police officers allows for critical early access to lifesaving therapy. ${ }^{2,3}$ We conducted an in-person needs assessment survey with local police departments and determined a significant lack of naloxone access. We designed a workflow for naloxone prescribing for those receiving >50 MED and supplied local police departments with naloxone.

\section{WHO AND WHERE}

This quality improvement project took place at Winding Waters Clinic, a Federally Qualified Health Center (FQHC) in rural northeast Oregon. The state of Oregon allows bystander administration of naloxone to persons suspected of having an opioid overdose. The clinic consists of full-scope family medicine clinicians working alongside integrated behavioral health, dental, and clinical pharmacy staff who also provide care at the local hospital. Opioid prescriptions in the tri-county area average 238 per 1,000 persons, compared with 144 per 1,000 persons in Oregon's largest urban county. The clinic's average MED was 41 as of May 2018 (mean 30 MED). ${ }^{4}$

\section{HOW}

This project was created to address 3 areas of interest: (1) to quantify opioid-prescribing patterns over time at the clinic, (2) to increase naloxone availability to patients prescribed greater

\footnotetext{
Conflicts of interest: authors report none.
}

\section{CORRESPONDING AUTHOR}

Nicholas B. West

1855 Earle St

Klamath Falls, OR 97601

wesni@ohsu.edu than 50 MED, (3) to provide naloxone to local law enforcement officers. Chart review identified patients prescribed opioids from January to May of 2018. We then calculated the MED for each patient and determined whether they had a prescription for naloxone. A total of $3.2 \%(n=132)$ of patients had an opioid prescription, with $0.08 \%(n=34)$ prescribed $>50$ MED with only 1 co-prescription for naloxone.

We then created a template note for the naloxone prescription information and pended naloxone prescriptions to the primary care clinician for each of the patients prescribed $>50$ MED. This way, the next clinician to see the patient would see the naloxone order. Six months after this workflow was implemented the number of naloxone prescriptions had increased. The significant lack of naloxone availability in our own clinic population caused us to question naloxone availability to local law enforcement. We held an informal in-person meeting with the Chief of the local police department who confirmed that none of the local city or county law enforcement vehicles carried naloxone, but it would have been of great assistance to his officers. Winding Waters Clinic then funded the purchase of 11 2-dose units of nasal naloxone to equip the county sheriff and city police, and our team provided a brief training on the effective use of the drug.

\section{LEARNING}

It is possible to run reports in some electronic medical records to identify MEDs and naloxone prescribing in a target population. Doing so better identifies how to develop a safe prescribing plan. Our workflow and public health efforts should help increase naloxone availability in the community and reduce opioid-related deaths. We believe that continued improvements to electronic health record reports will be critical to ensuring veracity of, and ease of access to, clinical data.

\section{References}

1. Dowell D, Haegerich TM, Chou R. CDC guideline for prescribing opioids for chronic pain - United States, 2016. MMWR Recomm Rep. 2016;65(1)(No. RR-1):1-49.

2. Davis CS, Ruiz S, Glynn P, Picariello G, Walley AY. Expanded access to naloxone among firefighters, police officers, and emergency medical technicians in Massachusetts. Am J Public Health. 2014;104(8):e7-e9.

3. Oregon Prescription Drug Overdose, Misuse, and Dependency Prevention Plan, 2015. Oregon Health Authority, Public Health Division, Injury and Violence Prevention Program, Nov 15, 2015. http://public.health.oregon.gov/PHD/Directory/Pages/program. aspx?pid $=10$

4. Oregon Health Authority. Prescribing and Overdose Data for Oregon. https://www.oregon.gov/oha/PH/PREVENTIONWELLNESS/ SUBSTANCEUSE/OPIOIDS/Pages/data.aspx 